\title{
Auto-Ethnography: Problems, Pitfalls and Promise
}

\author{
Emilia Sobolewska \\ Centre for Interaction Design \\ School of Computing \\ Napier University, Edinburgh \\ +44 (0) 1314552700 \\ e.sobolewska@napier.ac.uk
}

\author{
Colin F. Smith \\ Centre for Interaction Design \\ School of Computing \\ Napier University, Edinburgh \\ +44 (0) 1314552700 \\ cf.smith@napier.ac.uk
}

\author{
Phil Turner \\ Centre for Interaction Design \\ School of Computing \\ Napier University, Edinburgh \\ +44 (0) 1314552700 \\ p.turner@napier.ac.uk
}

\begin{abstract}
The teaching and perhaps more importantly the practice of ethnographic techniques has become increasing important within Human-Computer Interaction (HCI). But ethnography is also synonymous with in situ data collection over extended periods of time making it difficult to teach. This paper reports a study of the use of auto-ethnography by a group of undergraduate interaction design students. Auto-ethnography has the potential to expose these students to ethnographic concepts in a manageable fashion. The auto-ethnography required them to create a 'video-diary' of their use of an item of everyday interactive technology and then to write an analysis of their behaviour and their thoughts on how this might be used (while having fun). We identify problems and pitfalls, and offer advice for those who wish to repeat our endeavour.
\end{abstract}

\section{Categories and Subject Descriptors}

H.1.2 User/Machine Systems, Human factors, Human information processing.

\section{General Terms}

Design, Human Factors.

\section{Keywords}

Ethnography, auto-ethnography, interaction design.

\section{INTRODUCTION}

Ethnography is now recognised as being central to the practice of human-computer interaction (HCI) and there is a corresponding need to enable students to understand and engage in ethnographic practice. Ethnography, despite its origins in sociology and anthropology, has come to be something of a portmanteau term covering many, if not all, forms of data gathering with respect to 'user requirements' through to the naturalistic study of people using interactive technology. And although there are a number of unresolved questions as to what to do with ethnographic data, it is the method of choice for the contemporary HCI practitioner.

However, from a teaching perspective it is also recognised that ethnography is time consuming and presents a number of practical difficulties for the practitioner (e.g. issues concerning privacy and so forth). Our solution to this is auto-ethnography (also known as personal ethnography). So rather than unleashing HCI students on an unprepared world, they were required to create an autoethnography of their own everyday use of interactive technology. Instead of 'hanging around the workplace' students sat at home and talked to a camera about how they used their Xbox, MP3 player, mobile phone and so on, and how (if so) the appliances influence their everyday life.
Our aim is to write the paper we wish we could have read before embarking on this process.

\section{ETHNOGRAPHY}

Ethnography exists in many different forms which have been derived from its initial use in sociology and anthropology. The term "ethnography" means writing about the people (ethnos = people; graphien = writing), or in more illustrative words "portrait of a people". Ethnography consists of a methodology for studies of cultures and peoples, with the assumption that they have something in common - the experience of shared territory, religion and so on. It is descriptive, so the output from an ethnographic study is an ethnography which is a written account. The classic studies of adolescents in Samoa by Margaret Mead and exchange system of the Trobriand Islands by Bronisław Malinowski in the 1920 are famous examples of ethnographies [1, 2].

Ethno-methodological and ethnographic studies ([2, 3, 4, 5, 6) do not rest upon a generic model of work, but rather share an underlying philosophical approach to the study or work in context. They typically produce richly descriptive accounts, reflecting their sociological and anthropological lineages (respectively), whose contents and structure will vary from study to study depending on what is observed. Indeed, a strongly ethnographic approach is fundamentally incompatible with preconceived structures or models. Similarly, ethnographers generally have little to say about systems design, although there is now one study which proposes a bridge from rich ethnographic data to the systems design language UML [7] and others have suggested a role for the ethnographer as a facilitator for the designer [8].

\subsection{Design ethnography}

Design ethnography is a particular flavour of ethnography which has been developed with the intention of understanding how people use, interact and co-exist with technology. The design ethnographer typically being a social scientist who helps (technologists and designers) inform the design of new and existing products. The aim of design ethnography is to acquire a deep understanding of who the intended end users of your design are, what they do and what they want, and to understand the possible gaps (missing functionality or issues concerning aesthetics) in the current technology they use. In short, to recognize:

- the characteristics of the user

- patterns in their longitudinal use of the technology

- specific detail on how the technology is used in everyday life 
In all, to acquire a deep familiarity with other peoples' use of technology. For example, it has been reported [9] that Microsoft has recently hired a group of anthropologists to conduct ethnographic investigations. They have been reported as "showing up at 5 in the morning to observe a small businessman at close range, arriving as soon as he stepped out of the shower, then shadowing him until his workday ended at 10:30 p.m”. Called "Dawn to Dusk" the study documents the work habits and thought processes. They discovered that small companies kept vital information in disconnected places -- what she called "data silos" -- from scribbled notes on scraps of paper to files on a PC that could be accessed by only one employee.

This account is typical. So, ethnography can be seen as fieldwork with an emphasis on the naturalistic observation of people but in practice any kind of data collection which sheds light on people and their use of interactive technology (inc. questionnaire surveys, focus groups, in depth interviews). And ethnography also involves prolonged contact with 'a field'. It is this defining characteristic which provides a serious obstacle to the educator.

\subsection{A Diversity of Ethnographical Approaches}

As true ethnography takes a great deal of time and money "quick and dirty" ethnography has appeared. Of course, "quick and dirty" is the antithesis of traditional ethnography but there are many who would argue that it is better than nothing.

One such ethnographic 'short cut' that has become a popular tool is the 'cultural probe' [10]. Originally, cultural probes were packages of maps, postcards, and other materials designed to provoke inspirational responses from elderly people in diverse communities. Probes were given to these elderly people who then provided (typically via post) post, fragmentary data over time. The probes were part of a strategy of pursuing understanding of local cultures so that new designs wouldn't seem irrelevant or arrogant to those communities. Each probe contained: postcards, maps, a disposable camera, a photo album and a diary. The maps, for example, were accompanied by an inquiry exploring the elders' attitudes toward their environment. Participants were also asked to mark zones on local maps, showing where, for instance, they would go to meet people and where they would go to be alone.

In all, ethnography is invaluable, de rigueur for the modern interaction designer but since in practice it involves a considerable investment in terms of time and resources, this is a significant problem for those of us trying to teach it.

\section{AUTO-ETHNOGRAPHY IN PRACTICE}

\subsection{To whom it was taught}

The auto-ethnographical assessment was part of a level 8 (undergraduate) module entitled Practical Interaction Design. The assessment was assigned to a group of 69 students, $78 \%$ of whom were on the Interactive Media Design programme, with the remaining $22 \%$ of students being registered on Business Information Systems and Information Technology programmes with a smattering of students who had decided to take the module as an option. The assessment was also a component of a level 11 (postgraduate) module entitled Interaction Design, taken by a group of 20 students. Eight of these students were registered on a related 'specialist' programme of study (MSc Interaction Design the User Experience), where the Interaction Design module was a core element. This was a diverse group of students in terms of age and experience, a mix of recent graduates and people seeking either fresh impetus to their career or else a career change, They were mainly UK domiciled with two from overseas (US and Eastern Europe). The remaining 12 students were registered on a generic postgraduate computing programme, 'Applied Informatics'. This group largely comprised students who had recently completed an Undergraduate degree in computing in their own country, and were seeking a UK postgraduate qualification before entering the job market. The majority of this group were non-native English speakers from the Indian sub-continent.

\subsection{The assessment}

Students were required to create a video diary (an "autoethnography") of their use of some form of interactive media (e.g. the camera on their phone, MP3 player, TIVO etc.) and submit a written commentary with it. The requirements of the video diary were as follows:

- It must be created using the Apple iMovie application (chosen for its apparent ease of use)

- It should be between 30 - 45 minutes in length and cover a 3 week period of the use of technology. We suggested a minimum of three segments .

- The video diary should be professionally prepared and presented.

The written commentary was to be 500 words long and submitted as a Word document along with the movie file on a DVD. It should comprise analysis of the use of technology, and the recommendations, how these findings may be used to improve on the design of the technology involved or how it might be evaluated more effectively.

Students were marked for the professionally presented video diary, completeness and thoughtfulness of the commentary comprising the written analysis of the auto-ethnography and the thoughts as to how this analysis might be used.

Practical classes in support of the auto-ethnography were held over the period of six weeks, each lasting one hour in a Macintosh Laboratory. The first three weeks were utilised with learning to use iMovie, followed by three weeks dedicated to gathering the footage and editing it.

During the first two weeks, students received in-depth ( 2 hour) lectures. on ethnography and auto - ethnography. These covered the origins of ethnography, the use of auto - ethnography and its role in the design process.

The video-diary was chosen as a quite simple, yet engaging tool. The emphasis was placed on the fact that it was supposed to be fun and enjoyable - without strict rules. The students were encouraged to be playful and to get pleasure from playing with the technology and editing the movies.

\subsection{The technology}

Students were given freedom over the choice of technology used to record their auto - ethnographies. A number of mini-DVD camcorders were made available, to ensure that everyone had 'base-line' access to a recording device. They were encouraged to use any other recording device which they already had access to or had experience with, and many chose to use the camera on their mobile phones, This was particularly interesting in those cases where students also chose the use of their phone as the focus for the diary. Similarly, a number of students who decided to focus on 
their use of a digital camera in their diaries also used these as the recording device. Other novel choices included the built-in camera in their laptop or desktop computer (e.g. iSight in Macs), and web cams.

The videos were edited in iMovie ${ }^{\mathrm{TM}}$ or iMovie HD ${ }^{\mathrm{TM}}$, available in dedicated Macintosh Laboratory with 24 machines running Mac OS X.

\section{THE STUDENT EXPERIENCE}

\author{
"I liked this coursework because it made me analyse and \\ reflect on something I never think about."
}

"With honesty I can say that making this project gave me a lot of satisfaction and an opportunity to learn my computer a little bit better."

$M O$

We frequently used the metaphor of the 'time capsule' ${ }^{2}$ to encourage students to think about what they should include in their ethnographies. The students' task was to produce ethnographies that captured useful data on their use of the technology and whether/how it affected their lives.

The undergraduate students were divided into four groups, and each group had close support from a tutor (first author) when help was required. This was important especially for students on nonIMD programmes, many of whom were being exposed to digital media (using Macs) for the first time. The postgraduate students were taught as one group and supervised by a dedicated tutor.

Our first observation for all groups was that despite autoethnography being an individual perspective on their own technology use:

a) We noted significant cooperation between / among the students in handling both technical issues and matters of content too.

Students who started their projects early, encountered a variety of problems, particularly in mastering the iMovie software, (described below) and learned how to resolve them. They were all willing to share their experiences and offer help to other students who encountered similar obstacles. Many students preferred to seek peer assistance rather than consult their tutor. In some cases this could be attributed to the apparent simplicity of the iMovie application, and embarrassment at having difficulty in mastering it. In the case of the postgraduate students the homogenous group from South Asia were notable for their reluctance to call on assistance from their tutor, especially when in front of one another.

There were also instances of students helping each other with recording footage, especially if the clips were gathered in the field.

\footnotetext{
${ }^{1}$ The students' initials

${ }^{2}$ That is, what would the students put in a time capsule which would be buried and dug up in a hundred years time.
}

As to content, we noted cooperation between those students who had chosen to focus on similar interactive devices for their ethnographies. Some viewed the content of each others' videos to avoid repetition, some to gain other perspectives on the task, and others and to ensure they have not 'omitted' anything interesting.

b) In the written commentaries accompanying the video diary a number of students referred to themselves in the third person as 'the user' while discussing their own experiences,. This is evident in the extract below:

"The video diary was introduced explaining which device was to be used and how the user came to choose the Apple Macintosh Powerbook laptop computer. Although a bit disjoined, the explanation as to the choice of device made sense, as it was a device that was in daily use. The laptop would provide the range of features to analyse as the author explained in the introduction."

$S O O^{\prime} R$

In these written commentaries, some students stated that they found the interactive device itself more interesting than their own appearance on the video. Perplexingly, these students reported that they had decided to discard clips featuring their own reflections, focussing instead of footage illustrating the device.

"Since I'm very camera shy I finally decided to take a more artistic approach to the project, and skip the material with only me. Didn't feel good, and was not too informative. I thought it was easier too visually show how I use it. Since I don't talk too much I decided to add some music, quite calming and not too attentive. For me it's important that my viewer is enjoying the result."

"I definitely think that ethnographers, who after all are experts on this, could get some information out of it. I talk a little bit, but it's mostly to make it less boring. 30 minutes of me showing me doing things with a computer and a tablet isn't that funny. I do hope my message got through."

IO

Students were directed to choose an interactive technology that they use in their everyday life as the subject of their diaries, and all followed this instruction. Video diaries were produced focussing on their use of laptops or mobile phones (which included 'ordinary' mobiles, PDA phones and iPhones); some of them produced diaries about the software they used in school or for the work purposes, e.g. Adobe Photoshop ${ }^{\mathrm{TM}}$ and website development software. Some students talked about their digital cameras, others not unexpectedly shared their passion for their games consoles.

Table 1 (which can be found at the end of this paper) shows the data on which devices the Undergraduate students selected for their ethnographies, and what form the diary took. We quickly realised that the concept of a 'diary' was far from clearly understood. Out of 52 Undergraduate projects submitted:

12 clearly reflected the instructions given, in that the videos adhered to the form of a diary, where students recorded themselves over several days, covering different circumstances, and made significant points about their use of a particular technology during this particular time :

"I thought about the most popular camera use scenarios of an average person and I decided to take pictures in three 
different settings, i.e. night-time, daytime and interior. I have worked on this project for over a month's time, beginning with the night-time session at the Guy Fawk's Day [sic] Day fireworks display at the Meadowbank stadium. I took the daytime pictures at the seaside (of a boat and para-surfers) and inland (of an old church and a pathway to it). For the indoor session I chose to take pictures of a clock face and, using macro mode, part of accordion."

- 7 were made as 'show and tell' movies; the videos were usually divided into two or three chapters, showing how to use the device, with some additional personal comments on how it influence d (or not) the person's life, and how the device could be improved. This type of submission differed from the diaries described in the previous paragraph in terms of their length and the depth of the analysis they contained; they also tended to be less dynamic and, importantly, less, personal

"I was trying to record and mix the plot with reality when and how I was using the computer. Therefore I have showed all its functions and its usability. In the video I was talking about the usage of laptop functions which are really helpful. I have tried to create this video project in an easy and simple way that a receiver will understand it."

- 3 projects were constructed as set of clips, illustrated with music - the cuts did not contain any spoken commentary, but the pictures were powerful enough to provide an impression of what the student was trying to convey; the way that movie clips were edited showed a great deal of emotion, and a distinctly post - modern approach

"When a person uses the compuer [sic] like in my video, it is very nice to see, how they move, face expresions [sic] and body language. Most movements that we do wile we use the computer or any other item, are unctuous [sic]. That means we forget or don't realize what we have done with our hands during that time. We just remember the interaction of the screen and keyboard. It takes all your attention and you have to be highly concentrated (sic) to use them."

- 26 movies consisted of some sort of tutorial - very often in the form of 'expert knowledge' of video-games:

"My video diary is based on the game "Devil may cry 4" on the X-Box 360. The game is known to be one of the hardest games in existence and after looking online for a few videos on how to play the game better on youtube [sic] I left disappointed. Due to the lack of tutorial like videos on youtyube on the topic, this is where my idea came from."

"My video is of a technical perspective explaining how to deal with each boss before I fight them myself in full screen. There is a small introduction which is to explain to the viewer what the video is about and then jumps into the tutorial. There is no conclusion as the general public usually once they have the information they need they stop watching the movie, so after the last fight that is the end of the stage and the video." or 'Gadget show', when student have simply presented the device with all the available options and functions:

"The video diary has been based upon the Apple iPhone [sic]. To begin with we are introduced to what the video is about and then go on to describe the design of the iPhone and why it is so successful. We find out that this is because of the sleek design and lack of buttons making it slim and by not adding unnecessary bulk to it, it draws your attention to the phone with the shiny black back with visible apple logo which is an iconic symbol if you are seen with it."

$K M M$

Of course very often those two categories were overlapping.

- In 3 cases the files were wrongly exported and therefore unable to be watched.

The form of video produced also related to the form of students' on-screen appearance. Those who provided work in a diary format tended to record footage of themselves actually using the technology for almost the full length of the movie. 'Show and tells' and tutorials were recorded differently - the person and the technology were shown alternately on the screen, but almost never together. And while 'show and tell' movies had at least some footage of the student actually using the device, tutorials were less successful here. In the case of the 'Gadget show' style of presentation, the student tended not to appear in the recordings at all. The footage usually comprised a view of the device, the users' hands and a voiceover. Most of the submissions met the base-line coursework requirements - they were of appropriate length, and they were professionally edited in iMovie. However, despite the fact that the software offers quite a wide range of transitions and effects that can enhance the movie, students neglected these, with few exceptions. At most, some students took advantage of the capabilities of the application to produce videos that had simple transitions, separate chapters, a title page and end credits.

The form of the movie was also reflected in the form of the written commentaries provided. Students who demonstrated a good understanding of the concept of a video diary also produced very detailed, deep and meaningful analyses in their written commentaries, reflecting both on the data gathered, it's meaning, and often its utility.

"Technology shaped my life in many and many ways. It's even hard to see where and when cause I'm totally used to that. This video diary was a challenge, understand how Hi-Tech changed my life and where is not only laziness, obviously I failed.

I tried to show how it is present in my days, talking about everything I'm using right now. I mixed software and hardware stuff explaining how and why I'm using them, and what I think about how they shaped the everyone else life. I think that sometimes Technology is a pillar behind where we can hide, in certain way we need technology to feel safe, but obviously it fails in most of the cases.(...)

The conclusions are a bit sad; tech shaped my everyday life so deeply to scary me. I'm starting to think that Hi tech is a bad habit. I can't stay without Internet, I can't stop reading my email and going trough my favourite sites. I can't stop listen mp3 and so on. This video diary should be hours and hours long, but in the end I choose the things that simplify my everyday life in the silliest way or maybe I should say "on little details" cause I think that 
those "little details" are important to me and said more about Erik than I always thought."

Those students, who decided to choose alternative forms of expression, also produced different styles of commentaries. Those who produced 'movie clip' and 'show and tell' videos provided commentaries that concentrated more on the social aspects of particular technology:

"Why people like this technology so much? It is very easy to answer for it. People can find everything on Internet: they can buy, chat and work. Who use internet? In nowadays I think everyone, children who are six years old know how to surf on Internet, people after sixty use computers for mails.(...)

Unfortunately not everything is so fantastic and useful in internet. As such a big industry this technology can carry a very bad and destructive for the recipient information. Porn, crime, gambling sites can deliver malicious software, who will destroy our computer system"

$P M$

... while some commentaries demonstrated expertise in chosen subject matter (accompanied by 'tutorial' videos):

"My video supposed to give advice to people like me, gamers. I found that reading what others have done and are planning to do can show you what issues that might occur while trying to finish your work. This can also show you how to solve them or simply avoid them. Nothing is impossible and if there's an issue, then there is a solution, just need to find it and never give up."

$T K$

... or technical features ('Gadget show' videos):

"The K10D is a midsize digital SLR that's built like a tank. It's very solid, and all the "openings" (like the I/O port cover) are sealed for weather and dust resistance. The camera has a large right hand grip, so it's easy to hold. The camera has its fair share of buttons, though they are well-labeled and sensibly placed. The K10D has a 2.5" LCD that's typical of cameras in its class. Something not-so-typical anymore is the LCD info display on the top of the camera, which has a super-bright backlight for easy nighttime viewing. The camera supports basically all Pentax KAF mount lenses, and the K10D's Shake Reduction system means that every lens you attach will have image stabilization. The SR system serves another purpose on the K10D, and that's dust removal. When you turn on the camera you can have the SR system actually "shake" dust right off the sensor. Being a D-SLR, it shouldn't come as a surprise that tons of accessories are available, including lenses and flashes"

As an additional task, we offered students the option of publishing their movies on the www.youtube.com. This idea met with a range of reactions from the students, which can be grouped into two main categories:

a) Students who constructed their work as tutorials about a game, about software, or about the physical usage of a technology (e.g. upgrading a graphics card), were keen on presenting their work to the wider audience. They gladly agreed to put their clips online to get more feedback from other gamers/designers/technicians b) Students who were uncomfortable with the idea of exposing their work to a wider audience. Some of these students intentionally delayed the production of their work so as to avoid the whole issue, even though uploading their project was not compulsory. In this category we could place those students who provided submissions in a proper diary format, and who were uncomfortable at airing their personal reflections. The 'avoidance' attitude was also characteristic of those students who lacked confidence in the task.

The patterns apparent in the work of the undergraduate students are echoed, to some extent, in the work of the Postgraduates. Twenty submissions were received from the Postgraduate cohort. A minority of these videos, (albeit a large minority of 8) submitted work which adhered to the required diary format. However, an additional characteristic is apparent with some of the work in this group, which could be characterised as 'analysis incamera'. Four of these eight submissions were affected by this.

Students were requested to produce a reflective video diary of their use of an interactive technology, over time. The intention was that students would take the opportunity to reflect on their usage and the meaning of the technology for them, in a fairly spontaneous manner. 'Analysis in-camera' became apparent when students submitted diaries containing carefully measured, almost scripted analyses of their usage. The extent to which these reflections were spontaneous or else a result of careful crafting, is a moot point. It is certainly the case that the first-time viewer would have difficulty in believing they were watching an edited package of 'first take' material. In these cases, the written commentary, intended as the main vehicle for 'over-arching' analysis of the diary and the exercise as whole, was used to 'backup' analytical comments contained in the videos.

The remaining 12 submissions from the Postgraduate cohort were either 'show and tell', that illustrated the functionality and it's benefits from the user, or else 'gadget show', with sole focus on the device and it's capabilities.

\section{PROBLEMS, PITFALLS AND PROMISE}

The key question that has to be answered is, simply, , did this work? Almost inevitably, the reply has to be qualified. It worked for some. The non-media students were unexpectedly very engaged by the use of cameras and 'movie' making; for them it was interesting novelty, a great deal of fun, and a chance to change everyday routines. The specialist media students were a little 'sniffy' regarding iMovie (despite their problems using it) as being a little beneath them, especially as they had already used more professional editing software namely, Final Cut Pro.

Did it teach ethnography/ did the student learn something about ethnography? - more qualification. It is our suspicion that the many practical problems which the students faced (created for themselves is more accurate) masked, in part, our attempt for them to experience ethnography from the perspective of the interaction designer. That being said, it will be better next delivery.

At the outset of this paper we said that it was our intention to write the paper we would have liked to have read before we set out on this path. And rather than crying, 'don't do it' we offer 
three most frequently asked questions, followed by some practical advice.

The three most frequently asked questions were:

1. What subject should I pick?

2. How do I convert this file format to the one used by iMovie?

3. Why doesn't my movie have sound?

Practical advice:

1. Provide an explicit list of what we mean by interactive technology (MP3 players not washing machines), and the subjects that students may choose from. It may be, paradoxically, that in boundaries that we can actually release then from worrying about getting it wrong and release their creativity.

2. The students need to be told and shown what a diary is. Really. While we do not have any statistics on diary writing it was clear to us that the students needed to be exposed to (numerous) examples and counter-examples of diaries. This may be particularly important for non-European students. These examples might include Robinson Crusoe [11]; Pepys [12]; Adrian Mole [13] and perhaps movie clips and book pages of Bridget Jones $[14,15]$. Counter-examples might be drawn from TV programmes such as 'The Gadget Show' [16] or the BBC's Click (while this is UK specific, the name of the programmes is a fair reflection of the content) or any other 'show and tell' format. Click can be watched online at www.bbc.co.uk/click and is highly recommended.

3. Do not use iMovie or any other equivalent 'cut down' movie making application. While iMovie is an absolutely terrific application it imposes too many limitations of the range of file formats, professional project management and other special features for the budding film-maker. Use Final Cut Pro (or an equivalent instead). While it may be seen as complicated for non-media / HCI students it does provide more options, more straightforward tools, better usability and gives the feel of professional, industry equipment.

4. Provide technician support / or explicitly teach a quick ' 101 ' on connecting cameras to computers. Even with experienced students, sometimes there are technical difficulties which are tricky to overcome on their own. It is not enough to provide them with manuals, even for the software as simple as iMovie. Be particularly prepared to deal with issues such as how to merge audio and video in particular movie formats.

As for further work, we are grateful to the reviewers of this paper for their suggestions, the most appealing of which we shamelessly reproduce, namely, ask the students to carry out an ethnographic study on one of their colleagues rather than on themselves. However, we would recommend auto-ethnography as a worthwhile exercise and would like to be the first to wish you good luck.

\section{ACKNOWLEDGMENTS}

Our thanks to the students of IMD08101 and IMD11101 for their kind permission to quote from their work.

\section{REFERENCES}

[1] Malinowski, B., (1922) Argonauts of the Western Pacific. E.P. Dutton \& Co. Inc.:New York

[2] Mead, M., (1928) Coming of Age in Samoa. New York: William Morrow

[3] Bentley, Richard, Tom Rodden, Peter Sawyer, Ian Sommerville, John Hughes, David Randall and Dan Shapiro (1992). "Ethnographically-Informed Systems Design for Air Traffic Control". In Proceedings of CSCW '92, pp.123-129.

[4] Hughes, J., V. King, T. Rodden \& H. Andersen (1994). "Moving out from the control room: ethnography in system design", in Proceedings of CSCW '94, pp. 429-439.

[5] Pycock, J. and Bowers, J. (1996) Getting Others To Get It Right: An Ethnography of Design Work in the Fashion Industry. In M. S. Ackerman, Ed., Proceedings of CSCW '96, New York, ACM Press, 219-228

[6] Dourish, P. and Button, G. (1998) On

"Technomethodology": Foundational relationships between ethnomethodology and systems design, Human Computer Interaction, 13, 395-432.

[7] Viller, S. and Sommerville, I. (1999) Coherence: An approach to representing ethnographic analyses in systems design, Human-Computer Interaction, 14(1-2), 9-41.

[8] Twidale, Michael, David Randall and Richard Bentley (1994). "Situated evaluation for cooperative systems". Proceedings of CSCW 94 (Chapel Hill, North Carolina, USA), pp.441-452.

[9] www.inc.com/magazine $/ 20040601 /$ microsoft.html

[10] Gaver, W., Dunne, A and Pacenti, E. (1999) Cultural probes. Interactions January + February, 21-29.

[11] Defoe, D., (1719), The Life and Strange Surprizing Adventures of Robinson Crusoe, London, Printed for W. Taylor.

[12] Pepys, S. (1783-1853) The Diary of Samuel Pepys, Braybrooke, Richard Griffin, Baron

[13] Townsend, S. (1982) The Secret Diary of Adrian Mole, Aged $13 \frac{3}{4}$, Methuen

[14] Fielding, H., (1996), Bridget Jones's Diary, Penguin Books

[15] The Gadget Show (TV programme), Channel 5, 2008

[16] Bridget Jones (Sharon Maguire, MIRAMAX, 2001) 
--- Style of presentation ---

\begin{tabular}{|c|c|c|c|c|c|c|c|}
\hline Subject of auto-ethnography & $\mathrm{n}$ & $\stackrel{\vec{E}}{\frac{\pi}{0}}$ & 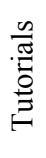 & 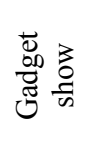 & 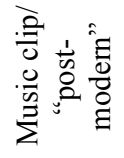 & $\begin{array}{l}\bar{\theta} \\
\text { d } \\
\frac{3}{0} \\
\text { क }\end{array}$ & $\begin{array}{l}3 \\
0 \\
\vdots \\
\vdots\end{array}$ \\
\hline xBox & 6 & 1 & 5 & & & & \\
\hline Laptop & 6 & 2 & 3 & & 1 & & \\
\hline MacBook, iMac & 5 & 1 & 3 & & & 1 & \\
\hline Software & 5 & 1 & 3 & & & 1 & \\
\hline Mobile & 3 & 1 & & & 1 & & 1 \\
\hline Camera & 3 & 2 & & 1 & & & \\
\hline iPhone & 2 & & & 2 & & & \\
\hline Game & 2 & & 2 & & & & \\
\hline Ubiquitous technology & 2 & 1 & & & & 1 & \\
\hline Mp3 player & 2 & & & 2 & & & \\
\hline SPS3 & 2 & & 1 & & & & 1 \\
\hline Mac vs PC & 2 & 1 & & & & 1 & \\
\hline Nintendo Wii & 1 & & & 1 & & & \\
\hline iPod touch & 1 & & & 1 & & & \\
\hline SPS1 & 1 & & & & & 1 & \\
\hline Car & 1 & 1 & & & & & \\
\hline Virgin Media & 1 & & & & & & 1 \\
\hline Console dashboard & 1 & & 1 & & & & \\
\hline $\mathrm{PC}$ & 1 & & & & & 1 & \\
\hline iSight & 1 & 1 & & & & & \\
\hline Upgrading graphic card & 1 & & & & & 1 & \\
\hline Internet & 1 & & & & & 1 & \\
\hline Skype & 1 & 1 & & & & & \\
\hline Tablet & 1 & & 1 & & & & \\
\hline
\end{tabular}

Table 1 Topics and forms of expression chosen by students 